\section{Counterpoint: Successes in the Pursuit of Precision Medicine: Biomarkers Take Credit}

Shumei Kato, MD; Vivek Subbiah, MD; and Razelle Kurzrock, MD

Recent years have ushered in technologies that have transformed our ability to interrogate the underlying abnormalities in individual tumors, including next-generation genomic sequencing, transcriptomics, and proteomics. As a result, numerous actionable molecular targets have emerged. There are currently $>70$ targeted agents FDA approved for the treatment of solid and hematologic malignancies, and the numbers continue to increase (http://www.mycancergenome.org/content/molecular-medicine/overviewof-targeted-therapies-for-cancer/). Further, immunotherapy has arisen as a new type of targeted therapeutic that specifically reactivates the immune system based on knowledge of checkpoints. Once reactivated, the immune system differentiates tumor cells from normal elements based on the neoantigens presented by the cancer cells as a result of the mutanome. Hence, the fields of genomics and immunotherapy, considered the pillars of precision medicine, are wedded to each other.

In his commentary elsewhere in this issue (page 859), Gyawali asks why an approach as attractive as precision medicine has failed to improve outcomes. He then proceeds to postulate the following explanations for this presumed failing: (1) the concept of precision medicine may be fallacious, and (2) the biomarkers used are inadequately validated. For the latter, he uses the examples of ERCC1 as a predictor of response to platinum agents and PD-L1 as a predictor of response to anti-PD-1/ PD-L1 checkpoint inhibitors.

Herein, we will show that precision medicine has already made substantial advances and has dramatically improved outcomes in several lethal cancers. Further, there are many remarkably useful biomarkers for response.

\section{Defining Precision Medicine}

Gyawali defined precision medicine as the concept of "tailoring treatment to individual patients based on the presence or absence of...biomarkers." We agree with this definition. There is now abundant evidence that metastatic tumors have complex genomic alterations that differ from patient to patient. Hence, in order to be precise in prosecuting them, one would need to personalize/individualize therapy. These concepts are the cornerstones of precision medicine.

\section{Has Precision Medicine Been a Failure or a Success?}

Gyawali claims that "precision medicine has failed to improve outcomes." To support this contention, he cites the SHIVA trial, which was a randomized "precision medicine" study. However, $80 \%$ of patients in SHIVA received monotherapy with either an mTOR inhibitor or a hormone modulator. ${ }^{1}$ Hence, it is reasonable to conclude that these 2 types of single agents given to patients with advanced refractory cancer are not effective. It is not justified to extrapolate from this limited data and conclude that all of precision medicine is a failure.

The precision medicine strategy has now transformed the outlook for several types of formerly deadly cancers. The poster child for advances based on molecular matching is chronic myelogenous leukemia $(\mathrm{CML}),{ }^{2}$ which had previously resulted

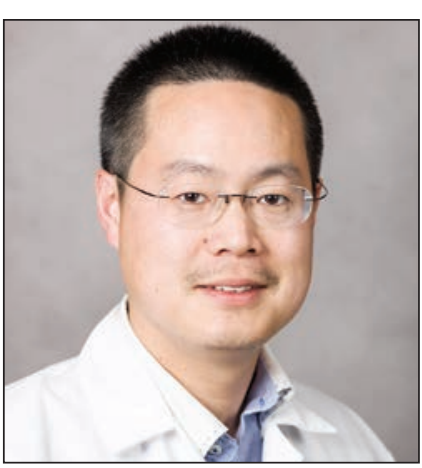

Shumei Kato, MD

Dr. Kato is an Assistant Professor of Medicine at University of California, San Diego. He treats a wide variety of cancers, including gastrointestinal cancer and rare tumors. His research focus is investigating the novel targeted therapy approach as well as understanding the resistant mechanism from targeted agents.

This work was funded in part by the Joan and Irwin Jacobs fund and by National Cancer Institute grant P30 CA016672 (RK) 


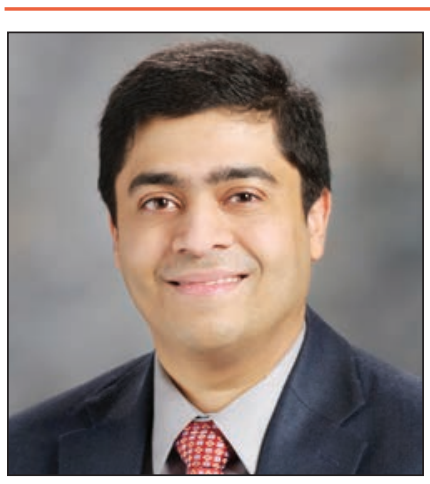

Vivek Subbiah, MD

Dr. Subbiah, a clinical trials investigator, is currently an Assistant Professor in the Department of Investigational Cancer Therapeutics (A Phase 1 Program), Division of Cancer Medicine, at The University of Texas MD Anderson Cancer Center. Dr. Subbiah has a unique training background in that he is one of the few physicians in the nation to have training in oncology in both adults and children. $\mathrm{He}$ is primarily involved in translational cancer research and the design/ conduct of early-phase, biomarkerdriven clinical trials, with a special interest in precision oncology and immunoconjugate trials. He is a major advocate for precision oncology and personalized medicine.

Dr. Subbiah receives research funding for clinical trials from Roche/Genentech, Novartis, Bayer, GSK, Nanocarrier, Vegenics, Northwest Biotherapeutics, Berghealth, Incyte, Fujifilm, Pharmamar, D3, Pfizer, Multivir, Amgen, Abbvie, and Bluprint Medicines. in inevitable death after approximately 4 to 5 years. However, the hallmark of $\mathrm{CML}$ is the aberrant Bcr-Abl enzyme, which can be targeted by the Bcr-Abl kinase inhibitor imatinib. Based on this precise approach, patients with CML now have a near-normal life expectancy. Another relevant example is the discovery of mutated KIT in gastrointestinal stromal tumors (GIST), a malignancy once considered to have a near-zero response rate to any treatment tried. Kit inhibitors have proven to be extraordinarily effective in GIST, with response rates of $>80 \%$ in patients with vulnerable KIT mutations. ${ }^{2}$

\section{Are the Biomarkers Available Effective in Predicting Response?}

Gyawali claims that the biomarkers used to predict response are inadequate. He cites 2 examples-ERCC1 and PD-L1. We agree that ERCC1 and PD-L1 may be imperfect biomarkers or, alternatively, that single biomarkers are unlikely to be completely predictive for complex tumors. In addition, both the biomarkers cited were immunohistochemistry (IHC)-based, a technique that has limitations such as variable antibody reactivity and subjective interpretation. Next-generation sequencing methods for biomarker detection have overcome the limitations of IHC and accelerated the precision oncology field. Indeed, studies show that matching patients based on IHC biomarkers improves outcomes, but not to the extent observed with genomic markers. ${ }^{3}$

There are now many biomarkers that have proven extremely useful in the cancer field. We described the remarkable improvements in outcome associated with the targeting of the product of the BCR-ABL rearrangement in CML or that of KIT mutations in GIST. Other similar examples of pharmacologically tractable genomic alterations include BRAF V600E in melanoma and other cancers, ${ }^{4}$ EGFR, ALK, and ROS1 alterations in non-small cell lung cancer (NSCLC), ${ }^{2}$ and HER2 expression in breast cancer. The evidence for the effectiveness of therapy matched to these alterations is indisputable (Table 1).

More recently, there have been trials that evaluated the use of the precision therapy approach in a broader sense. These studies include basket and umbrella trials. Basket trials focus on a specific mutation across multiple cancer types, whereas umbrella trials focus on a specific cancer type assigned to a treatment arm based on genomic profiling. A recent master protocol $(\mathrm{N}=500)$ that encompassed both the basket and umbrella concept (examining multiple alterations across diverse histologies) and permitted combination therapies showed that higher numbers of matches per patient (as reflected by a higher Matching Score) predicted improvement in all outcome parameters. ${ }^{5}$ Furthermore meta-analyses of approximately 85,000 patients demonstrated that biomarker matching independently predicted improvement in all outcome parameters. ${ }^{3,6,7}$

\section{Biomarkers for Immunotherapy}

Gyawali discusses the limitations of PD-L1 IHC as a biomarker for response to checkpoint inhibitor immunotherapy. This biomarker is indeed imperfect. Cutoff levels are not clearcut and tissue heterogeneity in PD-L1 expression is seen. Even so, across tumor types and anti-PD-1/PD-L1 agents, response rates in the presence of PD-L1 negativity are $0 \%$ to $17 \%$, whereas response rates in patients harboring PDL1-positive malignancies are $36 \%$ to $100 \%{ }^{8}$

Importantly, recent data suggest that other biomarkers are also extremely predictive of response to immunotherapy. For instance, patients with microsatellite 
Success in Pursuit of Precision Medicine

\begin{tabular}{|c|c|c|c|}
\hline Biomarkers & $\begin{array}{l}\text { Matched Targeted } \\
\text { Therapies }\end{array}$ & Cancer Diagnoses & $\begin{array}{l}\text { Approximate } \\
\text { Response Rates }\end{array}$ \\
\hline$A L K$ & $\begin{array}{l}\text { Alectinib } \\
\text { Ceritinib } \\
\text { Crizotinib }\end{array}$ & $\begin{array}{l}\text { Non-small cell lung } \\
\text { cancer }\end{array}$ & $60 \%-70 \%$ \\
\hline$B C R / A B L$ & $\begin{array}{l}\text { Bosutinib } \\
\text { Dasatinib } \\
\text { Nilotinib } \\
\text { Ponatinib } \\
\text { Imatinib }\end{array}$ & $\begin{array}{l}\text { Chronic myelogenous } \\
\text { leukemia } \\
\text { (newly diagnosed) }\end{array}$ & $100 \%$ \\
\hline$B R A F \mathrm{~V} 600$ & $\begin{array}{l}\text { Cobimetinib } \\
\text { Dabrafenib } \\
\text { Trametinib } \\
\text { Vemurafenib }\end{array}$ & Melanoma & $50 \%-60 \%$ \\
\hline$B R A F \mathrm{~V} 600$ & Vemurafenib & $\begin{array}{l}\text { Non-small cell lung } \\
\text { cancer } \\
\text { Erdheim-Chester } \\
\text { disease }\end{array}$ & $40 \%$ \\
\hline$B R C A$ & $\begin{array}{l}\text { Olaparib } \\
\text { Rucaparib }\end{array}$ & Ovarian cancer & $50 \%$ \\
\hline$B R C A$ & Olaparib & Prostate cancer & $86 \%$ \\
\hline$E G F R$ & $\begin{array}{l}\text { Erlotinib } \\
\text { Osimertinib (T790M) }\end{array}$ & $\begin{array}{l}\text { Non-small cell lung } \\
\text { cancer }\end{array}$ & $70 \%$ \\
\hline HER2 & $\begin{array}{l}\text { Lapatinib } \\
\text { Pertuzumab } \\
\text { Trastuzumab }\end{array}$ & Breast cancer & $\begin{array}{l}50 \%-70 \% \text { (combination } \\
\text { with chemotherapy) }\end{array}$ \\
\hline$K I T$ & Imatinib & $\begin{array}{l}\text { Gastrointestinal } \\
\text { stromal tumors }\end{array}$ & $50 \%-80 \%$ \\
\hline PDGFRA/KIT & Imatinib & $\begin{array}{l}\text { Hypereosinophilic } \\
\text { syndrome }\end{array}$ & $40 \%$ \\
\hline PDGFRB & Imatinib & $\begin{array}{l}\text { Dermatofibrosarcoma } \\
\text { protuberans }\end{array}$ & $80 \%$ \\
\hline $\begin{array}{l}\text { PD-L1/PD-L2 } \\
\text { amplification }\end{array}$ & $\begin{array}{l}\text { Nivolumab } \\
\text { Pembrolizumab }\end{array}$ & $\begin{array}{l}\text { Classical Hodgkin } \\
\text { lymphoma }\end{array}$ & $65 \%-87 \%$ \\
\hline ROS1 & Crizotinib & $\begin{array}{l}\text { Non-small cell lung } \\
\text { cancer }\end{array}$ & $70 \%$ \\
\hline $\begin{array}{l}\text { Microsatellite } \\
\text { instability }\end{array}$ & $\begin{array}{l}\text { Atezolizumab } \\
\text { Nivolumab } \\
\text { Pembrolizumab }\end{array}$ & $\begin{array}{l}\text { Any solid tumor, } \\
\text { including colorectal } \\
\text { cancer }\end{array}$ & $70 \%-80 \%$ \\
\hline
\end{tabular}

${ }^{a}$ All therapies except vemurafenib for non-small cell lung cancer and Erdheim-Chester disease, and olaparib for prostate cancer are FDA-approved.

Data from Overview of Targeted Therapies for Cancer. My Cancer Genome Web site. Available at: http://www.mycancergenome.org/content/molecular-medicine/overview-of-targeted-therapies-forcancer/. Accessed June 16, 2017.

instability/high tumor mutational burden have high response rates to checkpoint inhibitors. Further, some of these responders achieve durable complete remissions, even in the advanced, metastatic setting.

\section{Challenges and the Future of the Precision Cancer Therapy Approach}

Despite the recent advances observed with the precision cancer therapy approach, many patients still do not respond adequately. Indeed, genomics has revealed faults in our current paradigms for clinical research and practice. These problems will need to 
be addressed in order to fully realize the potential of precision medicine. For instance, the light microscope is still used to diagnose/classify cancer. This technology needs to be enhanced by the additional use of the "molecular microscope." Cancer is a genomic disease, and therefore genomics should be a key part of the diagnosis. ${ }^{9}$

Importantly, heterogeneity and genomic complexity are hallmarks of metastatic tumors and are among the major challenges to the current precision medicine approach. Indeed, each metastatic tumor appears to have a complicated and unique portfolio of molecular alterations. Yet, present-day precision medicine strategies often use traditional clinical trial designs. For instance, they frequently focus on single agents. Further, commonalities between patients are identified in order to treat them in a uniform way, despite the fact that each of their tumors has a distinct array of anomalies. Solutions to the problems of heterogeneity, complexity, and distinctiveness of each tumor include (1) using customized combinations of treatment rather than matched monotherapy for patients with metastatic tumors; (2) administering genomically targeted therapy earlier in the course of the disease, when there are fewer alterations and the tumor is less resistant; and (3) applying immunotherapy to patients with the greatest number of genomic alterations, because the immune system, once reactivated, bases its recognition and eradication of cancer cells on the degree of difference from normal elements- the more chaotic the tumor's genome, the better.

\section{Conclusions}

In the past few years, there have been remarkable advances based on precision medicine. These advances include, but are not limited to, the exploitation of specific genomic markers such as BCR-ABL, KIT, BRAF, ALK, and EGFR gene aberrations to identify individuals who will benefit from cognate targeted inhibitors. In addition, our understanding of the marriage between genomics and immunotherapy has yielded biomarkers such as microsatellite instability and high tumor mutational burden that can predict for dramatic responses to checkpoint inhibitors. Even so, realization of the full potential of precision medicine will require paradigm shifts that include more frequent application of genomic testing, use of tailored combination therapy ( $\mathrm{N}$-ofone strategies), and moving to earlier disease for genomically targeted therapy. Finally, developing a deeper scientific understanding of tumor complexity and of the function of the immune system will be critically important.

\section{References}

1. Le Tourneau C, Delord JP, Goncalves A, et al. Molecularly targeted therapy based on tumour molecular profiling versus conventional therapy for advanced cancer (SHIVA): a multicentre, open-label, proof-of-concept, randomised, controlled phase 2 trial. Lancet Oncol 2015;16:1324-1334.

2. Garay JP, Gray JW. Omics and therapy - a basis for precision medicine. Mol Oncol 2012;6:128-139.

3. Schwaederle M, Zhao M, Lee JJ, et al. Association of biomarker-based treatment strategies with response rates and progression-free survival in refractory malignant neoplasms: a meta-analysis. JAMA Oncol 2016;2:1452-1459.

4. Hyman DM, Puzanov I, Subbiah V, et al. Vemurafenib in multiple nonmelanoma cancers with BRAF V600 mutations. N Engl J Med 2015;373:726-736.

5. Wheler JJ, Janku F, Naing A, et al. Cancer therapy directed by comprehensive genomic profiling: a single center study. Cancer Res 2016;76:3690-3701.

6. Jardim DL, Schwaederle M, Wei C, et al. Impact of a biomarker-based strategy on oncology drug development: a meta-analysis of clinical trials leading to FDA approval. J Natl Cancer Inst 2015;107. pii: djv253.

7. Schwaederle M, Zhao M, Lee JJ, et al. Impact of precision medicine indiverse cancers: a meta-analysis of phase II clinical trials. J Clin Oncol 2015;33:3817-3325.

8. Patel SP, Kurzrock R. PD-L1 expression as a predictive biomarker in cancer immunotherapy. Mol Cancer Ther 2015;14:847-856.

9. Subbiah V, Kurzrock R. Universal genomic testing needed to win the war against cancer: genomics IS the diagnosis JAMA Oncol 2016;2:719-720. 